\title{
Liquid Phase Diffusion Bonding for Composite
}

\section{Tube Production*}

\section{Introduction}

Liquid phase diffusion bonding method has become applied during the past decade. The major characteristics of this method are to be able to reduce the bonding temperature and/or the applied pressure required for welding. The reason is generally that the interlayer material initially melts at a temperature below the melting points of base metals and fills the gaps between the mating surfaces.

Nippon Kokan has developed a new interlayer material, as shown in Fig. 1, which comprises a thin $\mathrm{Ni}$ foil with $\mathrm{Ni}-\mathrm{P}$ alloy layers on both surfaces. The melting point of $\mathrm{Ni}-\mathrm{P}$ alloy lowers with the increase in $\mathrm{P}$ content down to about $880^{\circ} \mathrm{C}$ at the eutectic composition. This interlayer material can be easily manufactured by an electroplating process as a wide and long sheet to bond a large surface area. Accordingly, liquid phase diffusion bonding using the interlayer material can be applied to the production of composite tube characterized by metallurgical bonding between outer and inner tubes and resultant high bonding strength.

\section{Manufacturing Process}

The interlayer material is wrapped spirally on an inner tube. After assembling the inner and outer tubes and cold-drawing to kill the gap between the tubes, heat treatment for liquid phase diffusion is performed in air at a temperature above $880^{\circ} \mathrm{G}$ for 15 to $60 \mathrm{~min}$. At this stage, if the thermal expansion coefficient of inner tube is greater than that of outer one, the difference may give rise to a pressure at the joining interface, thereby allowing the adhesion between them to ehnance.

Figure 2 shows composite tube of Incoloy 825 inside and API-X42 grade steel outside produced by the liquid phase diffusion bonding.

\section{Characteristics}

Main characteristics are summarized as follows:

(1) This method can provide sound bonding interface through a whole composite tube. In effect, no flakes, pores, bonding faults and other discontinuities were detected by the liquid penetrant test and ultrasonic inspection.

(2) Bend forming can be readi- ly performed as shown in Fig. 3 because of its high bonding strength which is more than $30 \mathrm{kgf} / \mathrm{mm}^{2}$ in a ring shear test.

(3) The selection of clad tube material can prepare various properties such as corrosion resistance and high temperature strength.

\section{Conclusion}

The composite tube produced by liquid phase diffusion bonding indicates excellent adhesion between outer and inner tubes. Therefore, the present composite tube is expected to be satisfactorily applied to line pipes, for example, of gathering line, chemical plant tube, boiler tube and oil refinery tube.

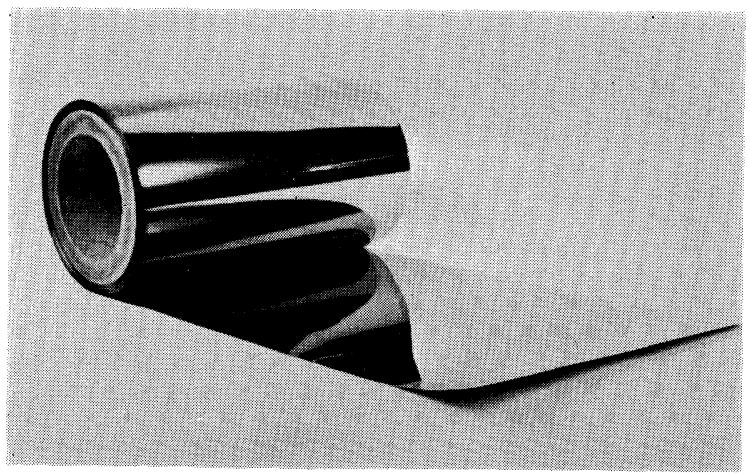

Fig. 1. Appearance of interlayer metal coated by electroplating.

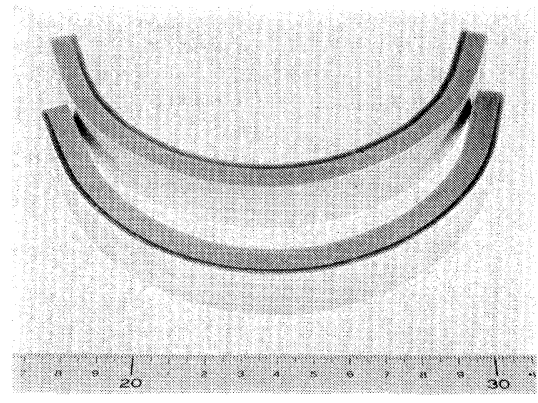

Fig. 3. Bend test result of composite tube consisting of Incoloy 825 inside and API-X42 grade steel outside.

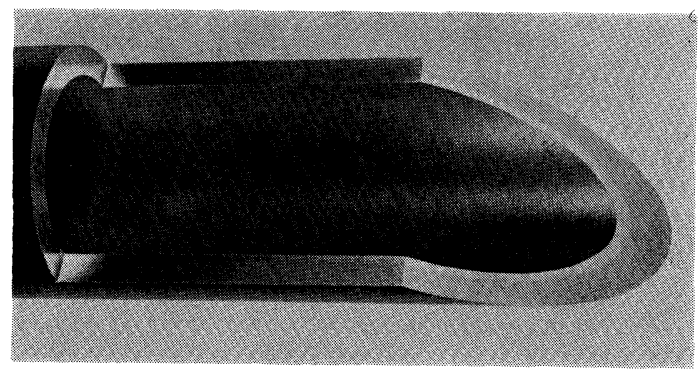

Fig. 2. Appearance of composite tube.

\footnotetext{
* For further information, write to Pipe and Tube Technology Department, Nippon Kokan K.K., 1-1, Minamiwatarida-cho, Kawasakiku, Kawasaki 210. (C) 1988 ISIJ
} 